\title{
Fecal Calprotectin in Patients with Hepatic Encephalopathy
}

\author{
Amany Lashin ${ }^{1}$, Tamer E. El-Eraky ${ }^{1}$, Waleed El-Eraky Al Azab ${ }^{2}$, \\ Amira Nour Eldin ${ }^{3}$ and Ahmed Abd Almaksoud Amer ${ }^{4}$ \\ ${ }^{1}$ Hepatology, Gastroenterology and Infectious Diseases Department, Benha University, Egypt \\ ${ }^{2}$ Neuropsychiatry Department, Benha University, Egypt \\ ${ }^{3}$ Clinical Pathology Department, Benha University, Egypt \\ ${ }^{4}$ Hepatology and Gastroenterology Unit, El Helal Hospital, Ministry of Health, Egypt
}

Corresponding Author

Ahmed Abd

Almaksoud Amer

Mobile:

$+201119892459$

E mail:

ahmedmaksoud83@ya hoo.com

Key words:

fecal calprotectin, liver cirrhosis, hepatic encephalopathy, WestHaven criteria, Child classification, MELD, number connection test
Background and study aim: Calprotectin is a cytoplasmatic protein of neutrophilic granulocytes and it is an established marker for the assessment of localized intestinal inflammation .Bacterial translocation is known to play an important role in the pathogenesis of certain complications of cirrhosis such as hepatic encephalopathy (HE). This study amid to assess: the value of fecal calprotectin in the diagnosis of hepatic encephalopathy, relationship between level of fecal calprotectin and the degree of hepatic encephalopathy.

Patients and Methods: This cross sectional study was conducted on 90 patients attended to the Hepatology, Gastroenterology and Infectious Diseases Department of Benha University Hospital between March and July 2016. All medical diseases which are known to influence the level of fecal calprotectin were excluded (as: gastrointestinal bleeding or inflmmatory bowel disease). The degree of liver insufficiency was assessed according to the Child Pugh classifiation and Model of End Stage
Liver Disease (MELD); and degree of hepatic encephalopathy by West-Haven criteria, and the number connection test.

Results: The mean value of fecal calprotectin in patients with overt HE was $304.4 \pm$ $41.05 \mu \mathrm{g} / \mathrm{g}$, and in patients with MHE was $74.4 \pm 23.9 \mu \mathrm{g} / \mathrm{g}$ and in the group of liver cirrhosis without encephalopathy was $57.55 \pm$ 8.92 and in healthy group was $25.22 \pm 8.63$, respectively with high significant difference $(\mathrm{p}<0.001)$. There was no significant correlation between fecal calprotectin and (age, psychometric test, Child-Pugh classification, MELD score and WestHaven criteria).

Conclusion: This study confirmed significantly higher values of fecal calprotectin in patients with hepatic encephalopathy. Among patints with $\mathrm{OHE}$ and patients of MHE, no significant correlation between fecal calprotectin and age, psychometric test, Child classification, MELD score and West-Haven criteria were detected.

\section{INTRODUCTION}

Calprotectin is a calcium and zincbinding protein, representing more than $60 \%$ of the cytosolic proteins in neutrophils. The presence of calprotectin in feces quantitatively relates to neutrophil migration into the gastrointestinal (GI) tract [1]. Therefore, it is considered as a valid marker of intestinal inflammation because it is released during cell activation and death [2].

As the GI tract of cirrhotic patients shows various alterations of its mucosal barrier including infiltrates of neutrophils, calprotectin might be a promising diagnostic parameter to diagnose the onset and course of hepatic encephalopathy [3].

There is extensive literature about the diagnostic significance of fecal calprotectin in patients with inflammatory bowel disease, non-steroidal antiinflammatory enteropathy and patients with irritable bowel disease, studies about the value of calprotectin in patients with cirrhosis are extremely sparse $[4,5]$.

Fecal calprotectin in cirrhosis was firstly investigated by Yagmur and others who found significantly elevated values in patients with advanced cirrhosis [6]. Significantly increased levels of fecal calprotectin in patients 
with cirrhosis confirmed by Gundling and others in their study [7].

Alempijević and his colleagues reported high significant values of fecal calprotectin in hepatic encephalopathy patients in comparison to liver cirrhosis and healthy subjects with significant correlation between FCC values and grades of hepatic encephalopathy according to WestHaven criteria [8].

\section{PATIENTS AND METHODS}

This study was performed on 90 patients attended to the Hepatology, Gastroenterology and Infectious Diseases Department of Benha University Hospital between March and July 2016 and divided into 4 groups. Group I: included 25 cirrhotic patients with minimal hepatic encephalopathy. Group II: included 25 cirrhotic patients with overt hepatic encephalopathy. Group III: included 20 cirrhotic patients without hepatic encephalopathy. Group IV: included 20 healthy subjects. The study was conducted according to the research plan of Hepatology, Gastroenterology and Infectious Diseases Department of Benha University.

Diagnosis of liver cirrhosis was based on clinical clues from the patient's medical history, physical examination, laboratory tests (CBC, ALT, AST, bilirubin, PT, PC, INR, urea, creatinin, HCVAb, HBSAg) and abdominal ultrasonography.

Quantitative estimation of calprotectin level in stool by an enzyme-linked immunosorbent assay (ELISA) according to the manufacturer's instructions $\left(\mathrm{EDI}^{\mathrm{TM}}\right.$ Quantitative fecal calprotectin ELISA, USA - KT- 849).

The degree of liver in sufficiency was assessed according to Child-Pugh classification of severity of liver disease and Model for End-Stage Liver Disease (MELD).

The degree of hepatic encephalopathy was assessed according to Number connection test and West-Haven criteria.

\section{RESULTS}

The study was conducted on 90 patients (54 male and 36 female), the mean age $49.92 \pm 8.86$ years
(61\% of patients were hepatitis C, $45 \%$ were hepatitis B).

This study showed statistical significant difference between studied groups regarding age \{mean age was highest in group I (52.72 \pm 9.03$)\}$. Regarding clinical examination, ascites was more frequent in group I and III (100\%) and jaundice was more frequent in group II (76\%).

This study showed statistically significant difference between the studied groups as regard to platelet count ,serum albumin, INR, bilirubin, SGOT and SGPT \{platelet was lowest in group II (114.12 \pm 59.27$)$ ], [Serum albumin was lowest in group I (1.99 \pm 0.35$)$, [INR was highest in group II (1.51 \pm 0.30$)]$, [T. bilirubin was highest in group II $(2.44 \pm 1.46)$ ], [SGPT was highest in group II (58.4 \pm 34.67$)$ ] and [SGOT was highest in group II (78.4 \pm 39.25$)]$. This study showed no statistical significant difference between studied groups as regard $\mathrm{Hb}$ and WBCs as shown in table (1)

As regard MELD score, there was no statistical significant difference between studied groups. But, there was statistical significant difference between diseased groups regarding Child classification [Child $\mathrm{C}$ was more frequent in group II (72\%)] while child B was more frequent in group III (75\%) as shown in Table (2)

As regard number connection test. There was statistical significant difference between studied groups: \{in group II there were $92 \%$ (grade III: forced termination) in comparison to group I there were $64 \%$ grade (I - II) as shown in table (3)

This study showed statistical significant difference between studied groups regarding fecal calprotectin \{fecal calprotectin was highest in group II (304.4 \pm 41.05$)$ in comparison to $(74.4 \pm 23.9)$ in group I, (57.55 \pm 8.92$)$ in group III and (25.22 \pm 8.63) in group IV \}as shown in table (4)

Among cases of group I (MHE), no significant correlation between fecal calprotectin and age, psychometric test, Child classification and MELD score. Among patients with OHE (group II), no significant correlation between fecal calprotectin and age, psychometric test, Child classification, MELD score and West-Haven criteria as shown in Table (5). 
Table (1): Laboratory data of the studied groups

\begin{tabular}{|l|c|c|c|c|c|c|}
\hline & $\begin{array}{c}\text { Group I } \\
\text { MHE } \\
(\mathbf{n}: \mathbf{2 5})\end{array}$ & $\begin{array}{c}\text { Group II } \\
\text { OHE } \\
(\mathbf{n}: \mathbf{2 5})\end{array}$ & $\begin{array}{c}\text { Group III } \\
\text { Without HE } \\
(\mathbf{n}: \mathbf{2 0})\end{array}$ & $\begin{array}{c}\text { Group IV } \\
(\mathbf{n}: \mathbf{2 0})\end{array}$ & Test & $\begin{array}{c}\text { P } \\
\text { value }\end{array}$ \\
\hline Hb mean \pm SD & $11.17 \pm 1.74$ & $11.16 \pm 1.39$ & $10.7 \pm 1.06$ & $11.11 \pm 0.85$ & $\mathrm{~F}=0.59$ & 0.62 \\
\hline Plt mean \pm SD & $127.8 \pm 62.97$ & $114.12 \pm 59.27$ & $133.4 \pm 61.64$ & $196.85 \pm 71.88$ & $\mathrm{~F}=7.04$ & $0.001 * *$ \\
\hline WBCs mean \pm SD & $6.52 \pm 2.88$ & $6.72 \pm 4.59$ & $6.41 \pm 2.22$ & $6.71 \pm 2.09$ & $\mathrm{~F}=0.05$ & 0.99 \\
\hline RBCs mean \pm SD & $3.75 \pm 0.62$ & $3.69 \pm 0.37$ & $3.84 \pm 0.92$ & $3.89 \pm 0.92$ & $\mathrm{~F}=0.34$ & 0.80 \\
\hline T Bilirubin mean \pm SD & $2.16 \pm 1.51$ & $2.44 \pm 1.46$ & $1.89 \pm 1.65$ & $0.98 \pm 0.14$ & $\mathrm{~F}=4.74$ & $<0.05$ \\
\hline S albumin mean \pm SD & $1.99 \pm 0.35$ & $2.16 \pm 0.58$ & $2.5 \pm 0.54$ & $3.77 \pm 0.24$ & $\mathrm{~F}=67.3$ & $0.001 * *$ \\
\hline SGPT mean \pm SD & $55.48 \pm 35.63$ & $58.4 \pm 34.67$ & $44.55 \pm 13.45$ & $32.5 \pm 3.97$ & $\mathrm{~F}=4.14$ & $<0.05$ \\
\hline SGOT mean \pm SD & $70.52 \pm 45.69$ & $78.4 \pm 39.25$ & $63.3 \pm 23.27$ & $28.8 \pm 4.07$ & $\mathrm{~F}=8.99$ & $0.001 * *$ \\
\hline $\begin{array}{l}\text { Proth.concentration } \\
\text { mean } \pm \text { SD }\end{array}$ & $57.08 \pm 12.33$ & $54.76 \pm 11.3$ & $66.05 \pm 13.45$ & $89.6 \pm 2.56$ & $\mathrm{~F}=45.4$ & $0.001 * *$ \\
\hline INR mean \pm SD & $1.47 \pm 0.24$ & $1.51 \pm 0.30$ & $1.39 \pm 0.24$ & $1.06 \pm 0.05$ & $\mathrm{~F}=16.83$ & $0.001 * *$ \\
\hline
\end{tabular}

$\mathrm{P}$ value $<0.05$ was considered statistically significant

Table (2): Assessment of severity of liver disease in cirrhotic groups

\begin{tabular}{|c|c|c|c|c|c|}
\hline & $\begin{array}{c}\text { Group I } \\
\text { OHE } \\
(\mathbf{n}: \mathbf{2 5})\end{array}$ & $\begin{array}{c}\text { Group II } \\
\text { MHE } \\
(\mathbf{n}: \mathbf{2 5})\end{array}$ & $\begin{array}{c}\text { Group III } \\
\text { Without HE } \\
(\mathbf{n}: \mathbf{2 0})\end{array}$ & $\mathbf{X}^{\mathbf{2}}$ test & P value \\
\hline MELD score & $14.92 \pm 5.6$ & $15.36 \pm 5.63$ & $13.2 \pm 5.25$ & $\mathrm{~F}=0.92$ & 0.40 \\
\hline Child classification & & 0 & 0 & & \\
A & 0 & $7(28.0)$ & $15(75.0)$ & FET $=89.94$ & $0.001 * *$ \\
B & $12(48.0)$ & $18(72.0)$ & $5(25.0)$ & & \\
C & $13(52.0)$ & & & & \\
\hline
\end{tabular}

Table (3): Number connection test in HE patients

\begin{tabular}{|c|c|c|c|c|}
\hline & $\begin{array}{c}\text { Group I } \\
\text { OHE } \\
(\mathbf{n}: \mathbf{2 5})\end{array}$ & $\begin{array}{c}\text { Group II } \\
\text { MHE } \\
(\mathbf{n}: \mathbf{2 5})\end{array}$ & FET & P value \\
\hline Number connection test & $8(32.0)$ & $0(0.0)$ & & \\
0-I & $16(64.0)$ & $0(0.0)$ & 56.22 & $0.001 * *$ \\
I-II & $1(4.0)$ & $2(8.0)$ & & \\
II-III & $0(0.0)$ & $23(92.0)$ & & \\
III (FT) & & & & \\
\hline
\end{tabular}

Table (4): Fecal calprotectin level in the studied groups

\begin{tabular}{|l|c|c|c|c|c|c|}
\hline & $\begin{array}{c}\text { Group I } \\
\text { MHE } \\
(\mathbf{n}: \mathbf{2 5})\end{array}$ & $\begin{array}{c}\text { Group II } \\
\text { OHE } \\
(\mathbf{n}: \mathbf{2 5})\end{array}$ & $\begin{array}{c}\text { Group III } \\
\text { Without HE } \\
(\mathbf{n}: \mathbf{2 0})\end{array}$ & $\begin{array}{c}\text { Group IV } \\
(\mathbf{n}: \mathbf{2 0})\end{array}$ & F Test & P value \\
\hline $\begin{array}{l}\text { Fecal calprotectin } \\
\text { mean } \pm \text { SD }\end{array}$ & $\begin{array}{c}74.4 \pm 23.9 \\
\mathrm{ug} / \mathrm{g}\end{array}$ & $\begin{array}{c}304.4 \pm 41.05 \\
\mathrm{ug} / \mathrm{g}\end{array}$ & $\begin{array}{c}57.55 \pm 8.92 \\
\mathrm{ug} / \mathrm{g}\end{array}$ & $\begin{array}{c}25.22 \pm 8.63 \\
\mathrm{ug} / \mathrm{g}\end{array}$ & $\mathrm{F}=584.7$ & $0.001 * *$ \\
\hline
\end{tabular}


Table (5): Correlation between fecal calprotectin and other variables among patients with (OHE) and patients with (MHE)

\begin{tabular}{|l|c|c|l|c|c|}
\hline \multicolumn{3}{|c|}{ Patients with (MHE) } & \multicolumn{3}{c|}{ Patients with (OHE) } \\
\hline Fecal calprotectin gp I & r test & P value & Fecal calprotectin gp II & r test & P value \\
\hline Age & 0.11 & 0.60 & Age & 0.15 & 0.48 \\
\hline Psychometric test & 0.16 & 0.46 & Psychometric test & 0.05 & 0.82 \\
\hline Child score & -0.09 & 0.67 & Child score & -0.39 & 0.054 \\
\hline MELD score & -0.20 & 0.34 & MELD score & 0.08 & 0.71 \\
\hline & & & West-Haven criteria & -0.25 & 0.23 \\
\hline
\end{tabular}

\section{DISCUSSION}

The diagnosis of HE continues to be a major clinical problem. Patients may present with mild cognitive impairment. It is important to recognize $\mathrm{HE}$ at their early stages because adequate treatment of the condition reduces morbidity and mortality [7].

Pathological bacterial translocation plays an important role in the pathogenesis of HE. Calprotectin is representing more than $60 \%$ of the cytosolic proteins in neutrophils. As the GI tract of cirrhotic patients shows various alterations of its mucosal barrier including infiltrates of neutrophils, calprotectin might be a promising diagnostic parameter to diagnose the onset and course of HE [3].

In this study, there was statistically significant difference between all groups as regard age $(\mathrm{P}<0.05)$. Mean age was highest in MHE group in comparison to OHE group cirrhotic group and control group (52.72 \pm 9.03$),(51.52 \pm 6.63),(48.7 \pm$ 8.27) (42.75 \pm 11.51$)$ respectively. Likewise, Akhtar and his colleagues reported that incidence of hepatic encephalopathy increased in elderly people in the study done on 294 elderly patients (age 65-97) [9]. This variation in age may be attributed to the diversity of eitiologies of liver cirrhosis and the impact of the course of disease progression.

As regard to sex, residence and smoking, there were no statistical significant difference between studied groups. This was in accordance with Butterworth [10]. But, this was against Manabendra and his colleagues who reported that incidence of hepatic encephalopathy was more in male than in female [11].

Regarding clinical examination, jaundice was more present in OHE group (76\%) and ascites was more frequent in [MHE group and cirrhotic group $(100 \%)]$. This was in agree with Hartmann and his colleagues and Thornton who reported that the incidence of hepatic encephalopathy is increased following the development of ascites and increased degree of jaundice $[12,13]$.

As regarding to hematological criteria, Platelet count showed highly statistical significant difference between studied groups (0.001). with the lowest level in OHE group in comparison to MHE group, cirrhotic group and control group (114.12 \pm 59.27), (127.8 \pm 62.97$),(133.4 \pm 61.64),(196.85 \pm$ $71.88)$ respectively. This comes in accordance with Gangireddy and his colleagues who reported that thrombocytopenia is a well-known complication in patients with liver cirrhosis and worsened with hepatic encephalopathy [14]. But, there was no difference regarding ( $\mathrm{Hb}$ concentration and WBCs).

As regarding to liver profile, INR was highest in OHE (1.51 \pm 0.30$)$ and serum albumin was lowest in MHE group (1.99 \pm 0.35 ). This was in agreement with Lee who reported that decreased synthetic capacity of liver as albumin and prothrombin observed in liver cirrhosis and aggravated with progression of disease and development of hepatic encephalopathy [15]. Bilirubin was highest in OHE group $(2.44 \pm 1.46)$ this comes in accordance with Hartmann and his colleagues who found increased degree of jaundice among HE patients compared with cirrhotic patients [16]. SGPT was highest in OHE group $(58.4 \pm 34.67)$ and SGOT was highest in overt hepatic encephalopathy group (78.4 \pm 39.25$)$. This study found no significant difference between the studied groups regarding viral markers.

In this study, there was significantly statistical difference between studied groups regarding ChildPugh classification. Child $\mathrm{C}$ was more predominant in OHE group (72\%) and Child B was more predominant in cirrhotic group $(75 \%)$.

In this study, comparison between studied groups as regard fecal calprotectin showed statistically high significant difference with the lowest value in control group $(25.22 \pm 8.63 \mu \mathrm{g} / \mathrm{g})$ followed by 
cirrhotic group $(57.55 \pm 8.92 \mu \mathrm{g} / \mathrm{g})$ followed by MHE group $(74.4 \pm 23.9 \mu \mathrm{g} / \mathrm{g})$ and the highest value in OHE group $(304.4 \pm 41.05 \mu \mathrm{g} / \mathrm{g})$ despite of a careful exclusion of other causes of abnormal calprotectin results e.g. GI bleeding.

These results come in accordance with Alempijević and his colleagues [8], Fatma and his colleagues [17], Gundling and his colleagues [7] and Yagmur and his colleagues [6] who found that median FCCs in high grade hepatic encephalopathy (380.7 $\pm 107.4 \mu \mathrm{g} / \mathrm{g}),(489 \pm 23 \mu \mathrm{g} / \mathrm{g}$ ), (median $321.6 \mu \mathrm{g} / \mathrm{g}$ ) and (median $429.38 \pm 74.90 \mu \mathrm{g} / \mathrm{g}$ ) respectively.

In this study, there was no significant correlation between fecal calprotectin and (age, psychometric test, Child-Pugh classification, MELD score and West-Haven criteria).

Alempijević and his colleagues reported nearly similar results and found no significant correlation between fecal calprotectin and ChildPugh classification. Also there was no significant correlation with MELD score and psychometric test [8]. But, Alempijević and his colleagues reported significant correlation between FCC values and grades of hepatic encephalopathy according to West-Haven criteria [8].

This was in partial disagreement with Gundling and his colleagues who revealed significant correlation between elevated FCCs and HE grading as measured by West-Haven criteria $(\mathrm{p}=0.001)$ and significant correlation with Child-Pugh classification and $M$ ELD score $(\mathrm{P}<0.001)$ and $(\mathrm{P}=0.018)$, respectively [7].

Also, Yagmur and his colleagues reported significant correlation between FCCs and ChildPugh classification $(\mathrm{P}<0.001)$ and $\mathrm{HE}$ grading as measured by West-Haven criteria $(\mathrm{p}=0.001)$ but, no significant correlation with MELD score [6].

Finally, fecal calprotectin may serve as a good screening tool for diagnosis of hepatic encephalopathy.

\section{CONCLUSION}

Fecal calprotectin level was shown to be significantly higher in cirrhotic patients in comparison with normal subjects. Fecal calprotectin level was shown to be significantly higher in cirrhotic patients presented with HE in comparison to cirrhotic patients.

\section{REFERENCES}

1- D' Inca R, Dal Pont E, Di Leo V, Benazzato L, Martinato M, Lamboglia F, et al. Can calprotectin predict relapse risk in inflammatory bowel disease?. Am J Gastroenterol 2008; 103: $2007-$ 2014.

2- Garcia-Tsao G and Wiest R. Gut microflora in the pathogenesis of the complications of cirrhosis. Best. Pract. Res. Clin. Gastroenterol 2004; 18: 353-372.

3- Ferenci P, Lockwood A, Mullen K, Tarter R, Weissenborn K and Blei AT. Hepatic encephalopathy definition, nomenclature, diagnosis, and quantification: final report of the working party at the $11^{\text {th }}$ World Congresses of Gastroenterology, Vienna, 1998. Hepatology 2002; 35 (3): 716-721.

4- Van Rheenen PF, Van de Vijver E and Fidler V. Faecal calprotectin for screening of patients with suspected inflammatory bowel disease: diagnostic meta-analysis. BMJ 2010; 341: 3369-3380.

5- Schoepfer AM, Trummler M, Seeholzer P, Seibold-Schmid B and Seibold F. Discriminating IBD from IBS: comparison of the test performance of fecal markers, blood leukocytes, CRP, and IBD antibodies. Inflamm. Bowel Dis. 2008; 14: 32-39.

6- Yagmur E, Schnyder B, Scholten D, SchirinSokhan R, Koch A, Winograd R., et al. Elevated concentrations of fecal calprotectin in patients with liver cirrhosis. Dtsch. Med. Wochenschr 2006; 131:1930-1934.

7- Gundling F, Schmidtler F, Hapfelmeier A, Schulte B, Schmidt T, Pehl C, et al. Fecal Calprotectin is a Useful Screening Parameter for Hepatic Encephalopathy and Spontaneous Bacterial Peritonitis in Cirrhosis. Liver Int. 2011; 31(9): 1406-1415.

8- Alempijević T, Stulić M, Popovic D, Culafic D, Dragasevic $\mathrm{S}$ and Milosavljevic T. The role of fecal calprotectin in assessment of hepatic encephalopathy in patients with liver cirrhosis. Acta Gastroenterol Belg 2014; 77 (3): 302-305.

9- Akhtar AJ, Alamy ME and Yoshikawa TT. Extrahepatic conditions and hepatic encephalopathy in elderly patients. Am J Med Sci 2002; 324 (1): $1-4$.

10- Butterworth RF. Hepatic encephalopathy. NORD 2011; https://rarediseases.org/rare-diseases/hepatic encephalopathy/.

11- Manabendra N, Anubhaw N and Nayak R. Incidence of hepatic encephalopathy in cirrhosis of liver. International Journal of Contemporary Medical Research 2016; 3 (12): 77-83. 
12- Hartmann MD, Michael Groeneweg MD and Juan CQ. The prognostic significance of subclinical hepatic encephalopathy. The American Journal of Gastroenterology 2002; 95: 2029-2034.

13- Thornton K. Evaluation and prognosis of patients with cirrhosis. Hepatitis C Online 2016; www.hepatitisc.uw.edu/go/evaluation-stagingmonitoring/evaluation-prognosis-cirrhosis.

14- Gangireddy VGR, Kanneganti PC, Sridhar S, Talla $S$ and Coleman T. Management of thrombocytopenia in advanced liver disease. Can J Gastroenterol Hepatol. 2014; 28 (10): 558-564.
15- Lee JS. Albumin for end-stage liver disease. Korean J Intern Med 2012; 27 (1): 13-19.

16- Hartmann MD, Michael Groeneweg MD and Juan CQ. The prognostic significance of subclinical hepatic encephalopathy. The American Journal of Gastroenterology 2002; 95: 2029-2034.

17- Mohamed IE and Ali-Eldin FA. Role of Fecal Calprotectin in Diagnosis and Follow up of Hepatic Encephalopathy. International Journal of Gastroenterology 2017; 2 (1): 7-11. 